\title{
El mundo extra europeo en el pensamiento de Tocqueville: occidente y el resto
}

\section{The Non-European World in the Tocqueville's Thought: the West and the Rest}

\author{
María Luisa Sánchez-Mejía ${ }^{1}$ \\ Universidad Complutense de Madrid (España)
}

Recibido: 23-02-19

Aprobado: 02-04-19

\section{Resumen}

Las reflexiones de Tocqueville sobre los pueblos y las culturas no occidentales están guiadas por dos preocupaciones principales. La primera, el lugar que debe ocupar Francia en el nuevo escenario internacional que se adivina tras la disgregación del Imperio otomano. Pero, hay, además, un interés intelectual genuino por la religión, las costumbres y la mentalidad de hindúes, musulmanes, chinos y amerindios. Sus textos y sus comentarios epistolares sobre estas regiones, muestran a un Tocqueville eurocéntrico pero con gran curiosidad por quienes son distintos, a veces crítico con los europeos, con ciertas esperanzas en el porvenir y siempre con grandes dosis de lucidez.

Palabras-clave: Tocqueville, colonialismo, cultura india, Islam, Argelia, pueblos amerindios.

\footnotetext{
Abstract

Tocqueville's thoughts on non-Occidental peoples and cultures are led by two main concerns. Firstly, he is worried about the role that France should play in

${ }^{1}$ (sanchezmejia@cps.ucm.es). Catedrática de Historia del Pensamiento político en la Universidad Complutense de Madrid. Especialista en el liberalismo del siglo XIX y en los fundamentos teóricos del imperialismo europeo. Publicaciones recientes sobre este tema: "Europa ante el espejo asiático: el debate sobre el despotismo oriental en el siglo XVIII" (2008); "Los intereses de Francia: Tocqueville y la cuestión colonial" (2009), "Barbarie y civilización en el discurso nacionalista de la Guerra de África" (2013), "La transformación de la herencia ilustrada: los argumentos del colonialismo en el siglo XIX" (2015).
} 
the future international scene foreseeing the Ottoman Empire's disassembling. But there is also a genuine intellectual interest on Muslim, Chinese and Amerindian religions, customs and mentality. His texts and comments about these regions show Tocqueville as Eurocentric, but very curious about those who are different, and sometimes critical with Europeans, with hopes in the future and always with doses of lucidity.

Key-words: Tocqueville, colonialism, India, Islam, Algeria, Amerindians.

El siglo XXI ha descubierto al Tocqueville imperialista. El gran teórico de la democracia, el liberal que admira las libertades americanas, no puede ya estudiarse, comentarse o investigarse sin su otro yo: el defensor de la conquista de Argelia, el profeta del exterminio de los amerindios o el nacionalista que quiere para Francia su parte del botín en la disolución del imperio otomano².

No es éste el tema central del presente artículo, aunque determinadas opiniones o actitudes resulten insoslayables. La intención es más modesta: explorar las reflexiones de Tocqueville sobre "los otros", sobre los pueblos y culturas que no forman parte del mundo occidental, atender a ciertos aspectos de su pensamiento político y de su imaginario cultural que completen su perfil intelectual y que sirvan quizá para esclarecer la imagen de la Europa de su época, esa Europa que debía afrontar pronto la llegada inexorable de la democracia.

No parece necesario insistir en que Tocqueville siempre escribe con la mirada puesta en Francia, sea para describir la democracia americana ${ }^{3}$, para proponer la abolición de la esclavitud o para intentar comprender el comportamiento de los pueblos de Argelia o de la India. Su condición de diputado en la Asamblea Nacional entre 1839 y 1848, representando al Departamento de Valognes, resalta aún más la preocupación francesa de sus reflexiones. Independiente políticamente y alejado de las pasiones que agitaban los debates, el diputado Tocqueville se veía a sí mismo como "un hombre nuevo con un espíritu libre y un amor ardiente por el gobierno representativo y por la dignidad del país", mientras se refugiaba en una soledad no exenta de altivez y adoptaba un cierto escepticismo sobre sus posibilidades de influir positivamente

2 Jennifer Pitts, "Empire and Democracy: Tocqueville and the Algeria Question", en The Journal of Political Philosophy, vol. 8, 3 (2000), pp. 295-318; A Turn to Empire. The rise of Imperial Liberalism in Britain and France, Princeton University Press, 2005. Demin Duan, "Reconsidering Tocqueville's Imperialism", en Ethical perspectives, 17, núm. 3 (2010), pp. 415-447. Cheryl Welch, "Colonial Violence and the Rethoric of Evasion. Tocqueville on Argelia", en Political Theory, 31 (2003), pp. 235-64; de la misma autora, "Out of Africa: Tocqueville's Imperials Voyages", [en Chistine Dunn Henderson coord. Tocqueville Voyages, Liberty Fund, 2014], pp. 304-334.

${ }^{3}$ La perspectiva francesa de La democracia en América ha sido especialmente puesta de manifiesto por Lucien Jaume, Tocqueville, les sources aritocratiques de la liberté, Paris, Fayard, 2008.

Araucaria. Revista Iberoamericana de Filosofia, Política, Humanidades y Relaciones Internacionales, año $21, \mathrm{n}^{\circ} 42$. Segundo semestre de 2019. Pp. 399-421. ISSN 1575-6823 e-ISSN 2340-2199 doi: 10.12795/araucaria.2019.i42.17 
en algo ${ }^{4}$. Representante del pensar filosófico del siglo XIX, Tocqueville es un hombre alejado ya de la pura especulación y conmovido en cambio "por las urgencias de la realidad”, como decía el profesor Díez del Corral ${ }^{5}$, lo que obliga al investigador a contemplar continuamente esas "urgencias" para entender mejor el sentido de su escritura.

Entre 1830, fecha del inicio de la conquista de Argelia por parte de Francia, y 1860 (un año después de la muerte de Tocqueville), Europa consolida su expansión por Asia, emprende con decisión el asalto a la ribera sur del Mediterráneo en vista de la debilidad del Imperio Otomano, y amplía sus enclaves en África, en espera del definitivo reparto de territorios que se llevará a cabo en la Conferencia de Berlín (1884-85). La joven república norteamericana contempla, en ese mismo periodo, su larga marcha hacia el Oeste, incorporando territorios a la Unión y enviando a las reservas a los amerindios. La rivalidad entre Francia y Gran Bretaña inflama los artículos en la prensa y los discursos en el parlamento. La política exterior se utiliza para oscurecer los problemas domésticos y la recientemente bautizada opinión pública devora todas las informaciones que dan cuenta de lo que sucede más allá de las fronteras del continente. El mundo se agranda, y los europeos perciben algo parecido a lo que nosotros llamamos hoy globalización. Así lo explicaba el economista Sismondi ya en 1814 :

"La suerte de todos los pueblos está relacionada en la actualidad, y la
prosperidad o desolación de las Molucas manifiesta su influencia hasta la
cumbre de los Alpes suizos. ¿Acaso no trabajan los talleres de Silesia para las
provincias más recónditas de la Confederación americana? ¿No estimula el lujo
de Perú y Méjico a la industria de las provincias mediterráneas, que confían a
otras naciones sus exportaciones?”

En esta situación no avanzar es retroceder. La convicción de que el planeta es un gran tablero donde se juega el poder y el honor de las potencias europeas, embarga a la opinión pública y hace florecer el patriotismo. La llamada “cuestión de Oriente" es la que ocupa más páginas en la prensa, más discursos en la tribuna parlamentaria y más actividad en las cancillerías. Las alianzas se hacen y deshacen y los tratados con cláusulas secretas se suceden.

La exclusión de Francia del Tratado de Londres de 1840 -que regulaba las relaciones de Europa con el Imperio Otomano- fue considerada en Francia como un insulto, como una ruptura del equilibrio europeo, como una

\footnotetext{
${ }^{4}$ Mary Lawlor, Alexis de Tocqueville in the Chamber of Deputies. His Views on Foreing and Colonial Policy, Whasington D.C., The Catholic University of America Press, 1959, p. 7.

${ }^{5}$ Luis Díez del Corral, El liberalismo doctrinario, Madrid, Instituto de Estudios Políticos, 1945, pp. 28-29.

${ }^{6}$ J.C.L. Simonde de Sismondi, Nouvelles réflexions sur la traite des négres, Géneve, Paris, J.J. Paschoud, 1914, p. 33. . La traducción de las citas es siempre mía, salvo indicación en contrario.
} 
marginación tan intolerable que merecía una respuesta bélica inmediata, una confrontación con Inglaterra, principal artífice del Tratado y culpable de la exclusión de Francia ${ }^{7}$. Convocadas las Cámaras en un clima de entusiasmo bélico, Tocqueville intervino con un discurso exaltado en la defensa del honor de Francia y de su necesario protagonismo en la escena internacional. Su síntesis expresa claramente "el espíritu de la época":

\begin{abstract}
“SSaben ustedes lo que pasa en Oriente? Es un mundo entero en transformación. Desde las riberas del Indo a los bordes del mar Negro, en ese inmenso espacio, todas las sociedades se tambalean, las religiones se debilitan, las nacionalidades desaparecen, las luces se apagan, el mundo asiático antiguo desaparece; y en su lugar se ve elevarse poco a poco el mundo europeo. La Europa de hoy no aborda sólo una esquina de Asia, como en la época de las Cruzadas; la alcanza por el norte, por el este, por el oeste, por todas partes, la perfora, la envuelve, la domina. ¿Creen ustedes que una nación que quiere seguir siendo grande puede presenciar tal espectáculo sin tomar parte en él? ¿Piensan que debemos dejar a dos pueblos europeos apoderarse impunemente de una herencia tan inmensa? Yo antes que sufrir eso, diría a mi país con energía: antes la guerra" ${ }^{8}$
\end{abstract}

\title{
Oriente en la lejanía
}

Francia iba en desventaja en la carrera imperial. Su presencia en la India no había podido consolidarse y desde 1761, fecha de la destrucción de Pondicherry por los británicos, los enclaves franceses dejaron de tener importancia y el campo quedó libre para las maniobras de la Compañía. La aparente facilidad con la que Gran Bretaña se había hecho con un territorio tan extenso y tan poblado causaba admiración y un cierto resentimiento en Francia, y más cuando Francia había sido pionera en el estudio de la religión y los textos sagrados de los indios, dando a conocer a Europa los tesoros literarios que el subcontinente encerraba.

El orientalismo francés había brillado desde finales del siglo XVIII, cuando Anquetil-Duperron, que pasó varios años en la India, aprendió sus lenguas y tradujo por primera vez uno de los grandes textos hindúes: el Zen-Avesta, publicado en francés en 1771, al que siguió pocos años después, en 1778, un largo tratado titulado Legislation Orientale ${ }^{9}$, en el que se daba a conocer a

${ }^{7}$ Las potencias firmantes del Tratado eran Gran Bretaña, Rusia, Austria y Prusia, decididas a sostener en ese momento al sultán. Francia fue excluida por su política de apoyo a Mehemet Alí, pachá de Egipto, en sus proyectos de independencia del gobierno de Constantinopla.

${ }^{8}$ Second Discours sur la Question d'Orient, en CEuvres Complètes, édition définitive publiée sous la direction de J-P. Mayer, Paris, Gallimard, 1962, vol. III, 2, pp. 290-91. Esta edición se citará en adelante como $O C$, seguida del número del volumen correspondiente.

9 Abraham-Hyacinthe Anquetil-Duperron, Législation Orientale. Ouvrage dans Lequel, en montrant Quels Sont en Turquie, en Perse et dans l'Hindoustan, les Principes Fondamentaux du Gouvernement ..., Amsterdam, M.M. Rey, 1778.

Araucaria. Revista Iberoamericana de Filosofía, Política, Humanidades y Relaciones Internacionales, año $21, \mathrm{n}^{\circ} 42$. Segundo semestre de 2019. Pp. 399-421. ISSN 1575-6823 e-ISSN 2340-2199 doi: 10.12795/araucaria.2019.i42.17 
los europeos el entramado jurídico-político de los imperios asiáticos. Estos primeros logros, hicieron que en Francia se creara una auténtica fascinación por la India. A pesar de la pérdida de sus territorios, los franceses continuaron dominando la indología en el siglo XIX, y fueron consolidando una imagen etnográfica de la India como tierra de hindúes, brahmanes y templos que han perdido su grandeza. Pensaban que los ingleses explotaban la India y destruían su cultura, un legado que podría recuperarse en parte bajo un benevolente gobierno francés. Estas percepciones se reflejan en los textos de Tocqueville sobre la India: las tensiones políticas, el interés cultural, la nostalgia de un pasado que pudo ser y no fue, la crítica colonial, el estudio etnográfico.... ${ }^{10}$

La redacción de sus primeras notas es de 1840 y el conjunto de los documentos que dejó escritos muestran una cuidadosa lectura de varios libros de historia, de política colonial y de antropología ${ }^{11}$. La relativa heterogeneidad de los textos da prueba de los dos intereses fundamentales de Tocqueville: explicar y explicarse cómo habían logrado los británicos conquistar la India tan fácilmente, y qué medidas de gobierno aplicadas en la India podían ser útiles a Francia para el gobierno de Argelia.

${ }^{10}$ Según indica André Jardin, el dossier LX de los manuscritos de Tocqueville agrupa los siguientes textos sobre la India: En primer lugar un proyecto de libro sobre el tema: Ébauches d'un ouvrage sur l'Inde. A. L'Inde (bonnes feuilles). [B. L'Inde. Plan de la suite de l'ouvrage] : I. Tableau de l'état de choses actuel dans l'Inde. II. Effets du Gouvernement anglais sur la condition des indous. III. Comment l'empire des anglais dans l'Inde pourrait être détruit. En segundo lugar unas Notes diverses sur l'Inde, que contienen: Novembre 1842, Réformes financières de Lord Cornwallis en 1789 (a) Établissement perpétuel, Justice-Établissement judiciaire des anglais dans l'Inde-Administration de la justice-Criminalité, Effets du gouvernement anglais sur la prospérité de l'Inde, Mahrattes, Afghans, Esclavage dans l'Inde, Notes diverses sur le gouvernement des anglais dans l'Inde, Notes sur la religion et la société indoues. El tercer bloque lleva por título : Note sur l'Inde en faisant en novembre 1841 la lecture de l'histoire de ce pays par M. Barchou de Penhoën. Y un cuarto apartado contiene : Notes prises sur le livre de l'Abbé Dubois. Idées suggérées par la lecture (a)-Été 1843. Y Jardin añade un último apéndice : Tocqueville, lecteur des lois de Manou, con notas breves sacadas del Manava-Dharma-Sastra, publicado en 1833 en francés por el orientalista Loiseleur-Deslongchamps bajo el título: Lois de Manou, comprenant les institutions religieuses et civiles des Indiens. OC, Vol. III, 1, pp. 441-553.

${ }^{11}$ De acuerdo con Jean-Louis Benoît, Tocqueville hizo una atenta lectura de las obras siguientes: Barchou de Penhoëm : Histoire de la conquête et de la fondation de l'Empire anglais dans l'Inde, 6. vol., Paris, 1841. Magnus Björnstjanera, Tableau politique de l'Empire britannique dans l'Inde, examen des probabilités de sa durée et de ses moyens de défense en cas d'invasion, traduction française, Paris, 1842. Jean-Antoine, abbé Dubois, Mours, institutions et cérémonies des peuples de l'Inde, 2. vol., Paris, 1825. Reginald Heber, Voyage de Calcutta à Bombay et dans les provinces supérieures de l'Inde pendant les années 1824 et 1825, suivi d'un voyage à Madras et dans les provinces méridionales, trad. française, 2 vol., Paris, 1826. Auguste Loiseleur-Deslongchamps, Les lois de Manou, 2. vol., Paris, 1830-1833. Sir John Malcolm, A Memoir of central India, 2. vol., Londres, 1832. Robert Montgomery Martin, History of the British Possessions in the East Indies, 2. vol., Londres, 1836. James Mill, The History of British India, 9 vol., Londres, 1840-1848. Alexis de Tocqueville, Notes sur le Coran et autres textes. Présentation et notes de Jean-Louis Benoît, edición electrónica : http://louprebel.fr/blog/documents/tocqueville_notes_coran.pdf, consultada el $14 \mathrm{de}$ Agosto de 2018.

Araucaria. Revista Iberoamericana de Filosofia, Política, Humanidades y Relaciones Internacionales, año $21, \mathrm{n}^{\circ} 42$. Segundo semestre de 2019. Pp. 399-421. ISSN 1575-6823 e-ISSN 2340-2199 doi: 10.12795/araucaria.2019.i42.17 
El primer punto necesita la comprensión de la historia, la cultura y la religión de la India, y a tal estudio se entrega Tocqueville siguiendo al padre Dubois, un misionero francés, que pasó allí más de treinta años. Convencido de que su éxito en la conversión de los indios pasaba por un buen conocimiento de la población a la que se dirigía, Dubois redactó un auténtico tratado etnográfico sobre la India, que llegó a ser en poco tiempo un manual imprescindible no sólo para los franceses interesados en el territorio, sino para los británicos, que tradujeron su obra al inglés y la popularizaron entre los oficiales del ejército y los servidores civiles del Imperio. Su principal foco de atención fue el sistema de castas y en especial la de los brahmanes, y ofreció siempre una imagen de una India hindú, sin atender a la parte musulmana, siguiendo la tradición de los indólogos franceses. Su admiración por la cultura hindú y por su propia patria, le llevó siempre a pensar que el pasado glorioso de la India podría recuperarse con ayuda de los franceses, en una propuesta más de la famosa "mission civilizatrice" tan utilizada más tarde por el colonialismo francés, y en curiosa sintonía con los deseos ya expresados por Raynal-Diderot en su Historia de las dos Indias ${ }^{12}$. Crítico de la colonización inglesa, a pesar del éxito de su obra entre los británicos, Dubois denunció las rapiñas del gobierno colonial en lo que fue una de las primeras críticas a la política económica de los ingleses, si bien reconoció que actuaban para erradicar algunas de las prácticas más abominables para los europeos, como el sati. A la postre concluyó que no se podía en realidad hacer nada por mejorar a los indios porque éstos no querían cambiar sus costumbres, y que era inútil cualquier misión, fuera religiosa o civilizadora ${ }^{13}$.

La guía de Dubois fue decisiva para trazar la imagen que Tocqueville se hizo de la India, y para la redacción de los borradores y notas que dejó sobre esta nación. Encontró en el abate un sólido argumento para explicar la fácil conquista de la India por los británicos: el sistema de castas. No llega a compartir con él la esperanza de que, en un futuro próximo, Francia tenga alguna posibilidad de recuperar influencia sobre la India. Tocqueville reitera en su obra el lamento por la pérdida de los enclaves franceses, por haber perdido la batalla por el dominio del subcontinente a favor de Inglaterra, precisamente al inicio de esa nueva era de expansión europea. Francia estaba entonces muy ocupada en su propia revolución y en conquistar a sus vecinos y no vio que la auténtica transformación se desarrollaba en el continente asiático y en el dominio de los mares: "El tumulto de Europa ocultaba el ruido que se levantaba en el fondo de Asia; durante 25 años los indios fueron olvidados y cuando las miradas se volvieron hacia ellos ya habían sido conquistados"14.

\footnotetext{
12 Jyoti Mohan, "British and French Ethnographies of India: Dubois and His English Commentators", en French Colonial History, Vol. 5 (2004), pp. 229-246

13 Jyoti Mohan, op. cit. , p. 233

$14 O C$, Vol. III, 1, p. 455.
}

Araucaria. Revista Iberoamericana de Filosofía, Política, Humanidades y Relaciones Internacionales, año $21, \mathrm{n}^{\circ} 42$ Segundo semestre de 2019. Pp. 399-421. ISSN 1575-6823 e-ISSN 2340-2199 doi: 10.12795/araucaria.2019.i42.17 
Fue una empresa fácil, porque los indios ya habían sido sometidos otras veces y aceptaban amos extranjeros, porque los príncipes estaban enfrentados unos con otros y porque la India no había llegado todavía al grado de civilización que lleva a querer defender el suelo patrio de toda invasión y presentar gran resistencia. En este último punto es donde se desgranan los argumentos más interesantes y los que podrían haber llevado a Tocqueville a una comparación con la situación en Argelia. "Se ha dicho que los pueblos de la India habían llegado ya a un estado de civilización muy avanzado. Por mi parte yo estoy convencido de lo contrario" $\mathrm{Y}$ anota:

"Leyes de Manu. Signos de infancia. Sociedad civil inmovilizada por la ley religiosa. [...] Conocían las ciencias y las artes, pero tenían todavía nociones imperfectas de unas y otras. Eran suficientemente civilizados para que un conquistador pudiera pillarlos por todas partes, en su persona y en su propiedad. No eran todavía tan sabios para haber aprendido el secreto de defenderse y el principal efecto de su civilización había sido atarlos a su bienestar antes que a su independencia" ${ }^{15}$.

Es un juicio en buena parte coincidente con el de James Mill en su historia de la India, publicada en 1817, cuando afirmaba que la India era una nación "semicivilizada", a juzgar por sus costumbres y sus leyes, su organización económica y social y su religión. Una civilización en definitiva que está en el mismo nivel que el resto de las culturas de Asia, la china, la persa y la árabe. Todas ellas son culturas estáticas que han evolucionado muy poco desde los tiempos antiguos y que deben afrontar ahora, piensa Mill, ciertos cambios de la mano de los británicos ${ }^{16}$. También a los argelinos los veía Tocqueville como salvajes o bárbaros (sin distinción entre ambos vocablos) y a los franceses como agentes del cambio, como ya veremos.

Sin embargo, la razón principal de que la India haya sido siempre presa fácil para conquistadores foráneos es la institución de las castas: "Todos los conquistadores han derribado los poderes políticos con facilidad pero cuando han querido tocar la casta han encontrado resistencias invencibles". "En la casta está encerrado el espíritu nacional de los hindúes. La patria para ellos es la casta, en vano buscarla en otro sitio, pero allí está viva" Por eso, "en un país de castas, la idea de la patria, de la nacionalidad desparece de alguna manera. No hay más que la casta y es demasiado débil para resistir". Y en esta situación "las revoluciones solo interesan a las castas superiores que están compuestas de un número muy reducido de personas, de manera que el poder que rige a millones de sujetos nunca está sostenido más que por los intereses o el esfuerzo de muy pocos" 17 .

\footnotetext{
${ }^{15}$ Ibid. p. 446 y ss. Las frases sin elaborar están así en el original, al tratarse tan solo de un borrador.

${ }^{16}$ James Mill, The History of British India, segunda edición, London, Baldwin, Cradock and Joy, 1820, libro II, cap. 10.

${ }_{17} O C$, Vol. III, 1, p. 447 y ss.
} 
Y la religión de los hindúes tampoco ayuda a crear un sentido amplio de pertenencia cultural y de resistencia ante agresiones exteriores. La religión de los brahmanes, a la que Tocqueville consagra muchas páginas en sus borradores, se presenta siempre bajo una opinión ambivalente.

Su politeísmo le parece supersticioso, pero considera la reencarnación como una creencia preferible a la negación de toda trascendencia, propia de los "materialistas": "No creo que todas las religiones sean igualmente verdaderas e igualmente buenas, pero pienso que no hay ninguna tan mala y tan falsa que no sea todavía una ventaja para un pueblo democrático el profesarla", dice en un texto que quedó finalmente inédito, y continúa: "Seguramente la metempsicosis no es más razonable que el materialismo. Sin embargo, si fuera absolutamente necesario que una democracia tuviese que elegir entre las dos, no dudaría, y juzgaría que sus ciudadanos se arriesgarían menos a embrutecerse pensando que su alma va a parar al cuerpo de un cerdo que creyendo que ésta no existe"18. No obstante en sus notas sobre la India acaba concluyendo: "La religión de los hindúes es abominable, la única, podríamos decir, que vale menos que la incredulidad" 19 .

Para Tocqueville, además, el brahmanismo es a la vez una religión absorbente y tolerante para con otras religiones, pero no es una tolerancia afín a los valores europeos de respeto por las creencias de otros. Es una tolerancia por indiferencia hacia los que están excluidos por nacimiento y nada pueden hacer por pertenecer a la casta superior. No hay odio a quienes Brahma ha dejado fuera, solo desapego y desdén. "Es la idea del origen común del género humano, de la similitud de los hombres y la obligación que tienen todos de conocer y rezar al mismo Dios, lo que ha introducido el proselitismo y la persecución en el mundo. Lo uno y lo otro han sido siempre ignorados en la India". Por eso la religión no les ha inspirado nunca la piedad furiosa que ha llevado a tantos pueblos a oponerse a la conquista cuando el conquistador profesa una fe distinta de la suya y que les ha llevado a salvar su nacionalidad al querer honrar su religión ${ }^{20}$.

Las observaciones de Tocqueville sobre la falta de sentimiento nacional en la India trascienden su interés etnográfico o cultural para mostrar su conexión con las cuestiones políticas que siempre interesaron a su autor. Hay una evidente relación entre nación y civilización en las consideraciones que dejó en sus borradores y en sus notas. O, más bien, entre patria y civilización. En La democracia en América alude al patriotismo en un doble sentido: como

${ }^{18}$ La democracia en América, edición crítica preparada y traducida por Eduardo Nolla, Madrid, Aguilar, 1988, Vol. II, segunda parte, cap. XV, p. 186. Todas las citas de esta obra se refieren a esta edición.

19 Jean-Louis Benoît (ed.), Alexis de Tocqueville, Notes sur le Coran et autres textes, edición electrónica: http://louprebel.fr/blog/documents/tocqueville_notes_coran.pdf, consultada el 14 de Agosto de 2018, p. 55.

${ }^{20} O C$, Vol. III, 1, pp. 448-449.

Araucaria. Revista Iberoamericana de Filosofia, Política, Humanidades y Relaciones Internacionales, año $21, \mathrm{n}^{\circ} 42$. Segundo semestre de 2019. Pp. 399-421. ISSN 1575-6823 e-ISSN 2340-2199 doi: 10.12795/araucaria.2019.i42.17 
amor instintivo por la patria cuando los pueblos son todavía sencillos en sus costumbres y firmes en sus creencias, "cuando la sociedad reposa plácidamente en un orden de cosas antiguo cuya legitimidad no se discute". Ese amor a la patria, dice en un párrafo luego tachado, "se encuentra en la cuna de las sociedades, preside los primeros tiempos de los pueblos"; y como amor racional, "que nace de la ilustración, se desarrolla con ayuda de las leyes, crece con el ejercicio de los derechos y acaba, en cierta manera, confundiéndose con el interés personal"21. Y, aunque no se pueda trazar ningún paralelismo, evidentemente, entre la Europa de las antiguas monarquías -donde Tocqueville cree encontrar el patriotismo instintivo- y la India del siglo XIX, resulta interesante ver cómo en sus notas la casta funciona como una patria que podría asimilarse al primer tipo de sentimiento de pertenencia, el de la historia, la costumbre y el reposo plácido en ese orden de cosas antiguo cuya legitimidad no es discutida. Cuando los conquistadores, que han derribado los poderes políticos con facilidad, "han querido tocar la casta, han encontrado resistencias invencibles", dice Tocqueville. Y no solo se desea pertenecer a la casta por razones religiosas sino por razones terrenales: estar fuera de la casta es colocarte fuera de la familia y de alguna manera fuera de la humanidad"22.

Lo que no se puede encontrar en la India es el patriotismo de la ilustración, las leyes y los derechos, que Tocqueville llama racional y adjetiva como republicano, y es también el que convierte a los hombres en ciudadanos y les liga a la patria a través de la defensa del interés individual y de la participación política, como sucede en América. En la India el sistema de castas es un sistema de opresión y de degradación para las castas inferiores, como la de los parias, que supone un cuarto de la población. Y rectifica al abate Dubois: Un indio sin casta es casi siempre un bribón, dice Dubois para probar la bondad de la existencia de castas, "no se da cuenta, apostilla Tocqueville, que es al contrario: los bribones son la consecuencia del sistema de castas. Los parias son despreciables y sin ley porque la opinión les desprecia y los coloca al margen de la ley"23. Sin leyes ni derechos, no hay nación en el sentido moderno, y civilizado podríamos añadir, del concepto.

Y en esto coincide con John Stuart Mill, que dedicó muchas más páginas que Tocqueville a la India. Para él también existe un nivel de cohesión nacional ligado a la historia común, la lengua, la religión y las costumbres, un nivel premoderno. Pero el concepto de nación debe sustentarse en la libre asociación de voluntades individuales que se unen en torno a unos valores compartidos o a unos principios proclamados públicamente, es decir que para Mill la nación supone una sociedad política. Y por eso afirma que "los bárbaros no tienen

\footnotetext{
${ }^{21}$ La democracia ..., vol. I, segunda parte, cap. 6. p. 232.

22 OC, vol. III, 1, pp. 447 y 537.

${ }^{23}$ Ibid. p. 537.
} 
derechos como nación"24. Si los indios desean llegar a gobernarse a sí mismos, deben primero alcanzar ese grado de integración nacional que ahora les falta. En las décadas centrales del siglo XIX, el concepto de nación ya se ha consolidado en su significado político posrevolucionario.

\section{Abrir las puertas de China}

Hoy Tocqueville es un autor muy leído en China. Hace unos años $E l$ Antiguo Régimen y la Revolución se convirtió en un auténtico best-seller en las librerías de Pekín. Los dirigentes chinos y las personas interesadas en la ciencia de la política han creído encontrar respuestas, o al menos cierta orientación, en las reflexiones del autor francés para situaciones de crisis de crecimiento y de gestión de problemas posrevolucionarios. Para unos, las consideraciones sobre la relación entre las mejores expectativas económicas y sociales y el estallido de la revolución resultan una advertencia alarmante, para otros resultan esperanzadoras $^{25}$. Tocqueville estaría tan sorprendido como nosotros por este éxito casi doscientos años después de la publicación de su obra, y en un país que era en muchos aspectos un arcano para los europeos.

En la primera mitad del siglo XIX Europa intentó acercarse a China desde ángulos más científicos. Siguiendo la tradición de los orientalistas del siglo XVIII, como William Jones o Anquetil-Duperron, el estudio de la lengua fue la empresa más importante. Desde la creación de la Academia de Lenguas Orientales, en París, en 1795, el interés filológico y académico por Oriente no había dejado de crecer. En 1822 la Sociedad Asiática de París se funda por iniciativa de Charles de Lasteyre y Abel-Rémusat, el gran sinólogo, que centró sus estudios en la lengua china e influyó notablemente en sus contemporáneos y en varias generaciones de lingüistas. Las familias de ambos mantenían relaciones de amistad con los Tocqueville, y otros orientalistas, como Burnouf y Jules Mohl estaban también en el círculo que frecuentaba el autor de La démocratie..., porque la aristocracia tenía en gran estima a los miembros de las "sociétés savantes", que proporcionaban un toque de distinción cultural muy apreciado en la época ${ }^{26}$.

Pero este mejor conocimiento de Oriente no hacía desaparecer los prejuicios y los tópicos arraigados en la cultura occidental. El adjetivo "chino" seguía siendo sinónimo de lo incomprensible o incluso lo perverso, a pesar

\footnotetext{
${ }^{24}$ John Stuart Mill, A few words of non intervention, Collected Works, J.M. Robson General Editor, vol. XXI, Essays on Equality, Law, and Education, Routledge \& Keagan Paul, 1984, p. 119

${ }_{25}$ The Tocqueville Review/La Revue Tocqueville, dedica su número 1 de 2017 a esta recepción contemporánea de Tocqueville en China y en Japón.

${ }^{26}$ Françoise Mélonio, "Tocqueville, la Chine et le Japon", en The Tocqueville Review/La Revue Tocqueville, vol. XXXVIII, 1 (2017), pp. 7-17.
} 
de que se publicaban también textos que intentaban mejorar la percepción de China, sin abandonar exotismos y lugares comunes. A la difusión de tópicos y prejuicios sobre China contribuyeron también los escritos del padre Huc, un discípulo de Abel-Rémusat, que publicó en 1850 Souvenirs d'un voyage dans la Tartarie, le Tibet et la Chine pendant les années 1844, 1845, 1846, leídos por Tocqueville en familia ${ }^{27}$, en los que combinaba una cierta admiración por las instituciones chinas con la idea de que los chinos son mentirosos, bribones y materialistas porque son paganos. La falta de una religión convencional no es ya una virtud, como lo había sido entre los ilustrados como Voltaire, sino un gran defecto. Incluso lo que a algunos les podía parecer un logro de la cultura china, como la meritocracia, les parecía a otros, como al propio Tocqueville, una visión de lo peor que podía traer a Europa la democracia. En el capítulo de De la démocratie... titulado "Por qué en Estados Unidos hay tantos ambiciosos y tan pocas grandes ambiciones", acusa a los concursos públicos, modo de selección democrática, de esta situación, por someter a todos "a una multitud de pequeños ejercicios preliminares entre los que pierden su juventud y su imaginación se extingue (...) y cuando llegan finalmente a poder llevar a cabo cosas extraordinarias, han perdido el gusto de ellas", como sucede en China:

\begin{abstract}
"donde la igualdad de condiciones es muy grande y muy antigua, un hombre solo pasa de una función pública a otra tras haberse sometido a una oposición. Esa prueba se repite a cada paso de su carrera y la idea está tan adentrada en las costumbres que recuerdo haber leído una novela china en la que el héroe, tras muchas vicisitudes, conmovió finalmente el corazón de su amada al pasar un buen examen. Mal pueden respirar a gusto las grandes ambiciones en semejante atmósfera" 28 .
\end{abstract}

Como nos indica Françoise Mélonio, la novela es $\mathrm{Lu} \mathrm{Kiao} \mathrm{Li}$, que se publicó a partir de 1826 en edición francesa de Abel-Rémusat. En ella el editor comparaba esta novela del siglo XV con el mundo europeo del XIX, y aseguraba que "la ciencia y el talento abren infaliblemente el camino de la fortuna y allanan el acceso a las más altas dignidades"29

Pero Tocqueville tiene un interés distinto en la China que en la India. En este último país hubiera deseado que Francia reemplazara a los británicos y quizá, de manera un tanto idealizada, un colonialismo más humano buscando mayor igualdad entre ambos pueblos, al menos a largo plazo. Se indigna cuando Lord Canning, Gobernador general de la India, consuma la anexión de la provincia de Oudh a la corona inglesa: "Los bárbaros que invadieron el Imperio Romano, los normandos que conquistaron Inglaterra, incluso los

\footnotetext{
${ }^{27}$ Ibid.

${ }^{28}$ La democracia ..., vol. II, tercera parte, cap. XIX, p. 291.

${ }^{29}$ Françoise Mélonio, op. cit.
} 
españoles en América, nunca procedieron con una violencia tan enorme como esta desposesión de todo un pueblo"30. Cuando se trate de Argelia y no de la India, su indignación no sonará tan fuerte, como veremos.

Sobre China en cambio no habla como un francés, como un nacionalista francés -como sí lo hará sobre Argelia-, sino como un imperialista europeo, sin más. China y Japón eran, al igual que el África subsahariana, dos enclaves cerrados, vedados al comercio con Europa. Y eso resultaba inaudito, insoportable, podríamos decir: "No encontraría consuelo en no ver por fin, antes de morir, la China abierta, y el ojo de Europa penetrando en ella con su armas", escribe en $1857^{31}$. Compartía la idea de muchos de sus contemporáneos que veían en China, más allá de la admiración de los orientalistas, un país atrasado, despótico, lleno de gentes de mala fe $\mathrm{y}$, sobre todo, que se negaba cerrilmente a entrar en los intercambios comerciales, en ese "doux commerce", como lo habían llamado los ilustrados, signo de civilización y garantía de un mundo mejor cuando el comercio hubiera sustituido a la guerra ${ }^{32}$. China era el contraejemplo, lo que no debía ser, lo que debía dejar de ser: "Cuando quiero darme el gusto de sentirme orgulloso de mi época y de mis contemporáneos, pienso en Oriente y en particular en China. Si nos comparamos con los cobardes bribones que pueblan esta parte del mundo me produce la ilusión de que somos grandes hombres"33. Tocqueville aplaudió la expedición a China y a Cochinchina que organizó Napoleón III en 1858, y murió un año antes de la ocupación de Pekín por los europeos.

\section{EI Islam y los pueblos del Magreb}

En sus textos sobre la India, Tocqueville apenas se ocupó de la población musulmana del país. En sus Notes sur la religion et la société indoues se limita a decir que "El despotismo gubernamental de las instituciones mahometanas es infinitamente mayor, a pesar de lo que diga Mill, que el derivado de las instituciones brahmánicas. Los dos poderes reunidos en la misma mano"34, para continuar, antes y después de esta observación, describiendo la religión y la sociedad hindú.

Sin embargo, la presencia de Francia en Argelia le llevó a ocuparse de la religión islámica y de los pueblos árabes. E1 22 de octubre de 1843 escribe a Gobineau: "Estudié mucho el Corán por nuestra situación frente a las

\footnotetext{
${ }^{30}$ Lettre du 13 may 1858 à Reeve, $O C$ vol. VI, 1, p. 264

${ }^{31}$ Lettre du 8 mars 1857 à Senior OC, Vol. VI, 2, p. 199

${ }^{32}$ Montesquieu, De l'esprit des lois, XX, 1

33 Françoise Mélonio, op. cit. p. 11.

${ }^{34} O C$, Vol. III, 1, p. 508.
} 
poblaciones musulmanas en Argelia y en todo Oriente" 35 . En efecto, después de publicar sus dos Lettres sur l'Algérie en $1837^{36}$, Tocqueville inició, en marzo de 1838 , la lectura del Corán para poder entender mejor a las poblaciones que habitaban el país que Francia estaba dispuesta a colonizar. De esta lectura nos han quedado unas Notes sur le $\operatorname{Coran}^{37}$, breves resúmenes ordenados por capítulos que, según el editor de las Oeuvres Complètes son siempre literales, aunque a veces se limita a decir simplemente "nada nuevo", "nada de particular ni de práctico". Las notas se interrumpen bruscamente en una anunciado "Capítulo XIX".

En una carta a su primo Louis de Kergorlay nos ofrece algunas conclusiones de esta lectura: "El Corán no es más que un compromiso bastante hábil entre el materialismo y el espiritualismo". Mahoma (...) destaca los preceptos relativos a la obediencia ciega al profeta, la guerra santa como la primera de las buenas obras, y otros que tienen un indudable resultado práctico, en su opinión. Considera que es una progreso sobre el politeísmo porque contiene "nociones más claras y verdaderas sobre la divinidad y promueve de manera más extensa y más nítida algunos deberes generales de la humanidad". Pero, finalmente, cree que quizá su lectura haya producido más males que bienes y que la gran influencia de Mahoma sobre la especie humana ha sido "más perjudicial que salutífera" $"$.

Y si nos fijamos en la práctica de la religión y en el culto musulmán, Tocqueville destaca, por un lado, la escasa importancia del clero y de la organización eclesiástica, pero, por otro, la fuerte unión entre autoridad religiosa y autoridad política: "El mahometismo es la religión que ha confundido y entremezclado más completamente los dos poderes; de manera que el gran sacerdote es necesariamente el príncipe, y el príncipe el gran sacerdote, y todos los actos de la vida civil y política se regulan más o menos por la ley religiosa". Esto es en realidad un bien -dice Tocqueville poco dado al clericalismo-porque los cuerpos sacerdotales son con frecuencia la fuente del malestar social, y si la religión puede brillar sin necesidad de este peligro, hay que alabarla. Pero, por otra parte, continúa, esta unión "es la primera causa del despotismo y sobre todo del estancamiento social que ha caracterizado casi siempre a las naciones musulmanas y que ha llevado a todas finalmente a sucumbir ante las naciones que han adoptado el sistema contrario"39.

En 1841 Tocqueville emprende su primer viaje a Argelia para confrontar sus lecturas del Corán y sus reflexiones sobre la religión islámica con la forma

\footnotetext{
${ }^{35} O C$ Vol. IX, p. 69.

${ }^{36} O C$, Vol. III, 1, pp. 129-153.

${ }^{37}$ Notes sur le Coran, OC, Vol. III, 1, pp. 154-162.

${ }^{38} O C$, Vol. V, p. 354; OC, Vol. XIII, 2, pp. 28-29. Ver Benoît, p. 30.

39 Notes prises avant le voyage d'Algérie et dans le courant de 1840, OC, Vol. III,1 p. 174.
} 
de vida y el carácter de los pueblos que habitaban la antigua Regencia de $\operatorname{Argel}^{40}$. Allí se encuentra con el contraste llamativo entre los kabyles, cabileños, y los árabes. Los franceses creían que sería más fácil entenderse con los habitantes de la Cabilia que con los árabes porque aquellos eran sedentarios, agricultores y comerciantes. "Construyen casas, dice Tocqueville, saben explotar minas de hierro... y elaboran toscos tejidos"41. Los primeros filólogos que se ocuparon de su lengua vieron en ella una connotación de mayor arraigo en la tierra, en el territorio, una vinculación más nacional, frente a la filiación más tribal de la lengua y del comportamiento árabe. Los franceses se identificaban más con la primera actitud ${ }^{42}$. Pero, a la vez, Tocqueville los veía muy cercanos al buen salvaje roussoniano, como individuos libres y solitarios que disfrutan de su primitiva independencia; ni ricos ni pobres, ni servidores ni amos, nombran a sus propios jefes y están contentos y acomodados a su suerte. Pero no hay finalmente mucha idealización de ese estado natural, porque "para ellos no hay más ley que la fuerza", y viven tan aislados que si apareciera un extranjero en su territorio, aunque solo fuera para conversar, sin duda le cortarían la cabeza ${ }^{43}$. La Cabilia resistió durante más de quince años, y en realidad su conquista requirió más esfuerzo que el dominio de la llanura donde habitaban los árabes, pero estos montañeses, considerados rudos y elementales, conservaron durante mucho tiempo las simpatías de los franceses porque sabían defender con orgullo y tenacidad la tierra que habitaban y cultivaban, y eso les hacía más cercanos a los europeos que el imaginado nomadeo constante de los árabes.

La connotación negativa del nomadismo procede fundamentalmente de las dificultades que oponía al control por parte del ejército francés. No servía de nada ocupar un territorio si no implicaba también ocupar pueblos o aldeas y someter a control a sus habitantes. Los árabes siempre retrocedían ante el avance de las tropas; no defendían ni tierra, ni ciudades, ni cultivos; se escapaban, se escurrían en la inmensidad del desierto, para volver en cuanto el ejército se desplazaba a otro lugar. Era evidente que no todos los árabes eran nómadas y que la estampa exótica de camellos y jaimas solo podía encontrarse al sur del territorio, y se reconocía también, como hace Tocqueville, que buena parte de la tierra tenía propietarios y títulos de propiedad redactados ante un funcionario público, pero la imagen de la vida errante, sin domicilio

\footnotetext{
${ }^{40}$ Una información más detallada de la visión de Argelia desde Francia se puede encontrar en mi artículo "Colonialismo y alteridad: el debate racial y cultural en la conquista de Argelia", Araucaria. Revista Iberoamericana de Filosofia, Politica y Humanidades, 36, (2016).

${ }^{41}$ Première lettre sur l'Algérie (23 Juin 1837), OC, Vol. III, 1, pág. 131. Hay edición española de las Dos cartas sobre Argelia y del Trabajo sobre Argelia, en Escritos sobre la esclavitud y el colonialismo, edición de María Luisa Sánchez-Mejía, traducción de Ana Portuondo, Madrid, Centro de Estudios Políticos y Constitucionales, 2007.

${ }_{42}$ Patricia M.E. Lorcin, Kabyles, arabes, français: identités coloniales. Presses de 1'Université de Limoges, 2005, p. 66.

43 Première lettre sur l'Algérie, OC Vol. III, 1, p. 132.
} 
fijo y sin ocupaciones cotidianas era predominante: "Distan de haberse hecho enteramente sedentarios: tienen casas unos pocos, los más siguen viviendo en tiendas según su antigua usanza. "Cada tribu tiene su territorio, baldío casi siempre o cultivado con poca destreza. Están en situación de transición, entre la vida nómada y la sedentaria. Al sur ya no hay linderos ni mojones ni títulos de propiedad, solo la soledad del desierto. Y completa así el retrato de los árabes:

"la imaginación brillante y sensual, el ingenio agudo, sagaz, el coraje y la inconstancia que exhibían sus mayores. Como aquellos, pertenecen a esa raza mudable e indómita que adora los placeres físicos... Desconfiados y crédulos, tan pronto son presa de irreflexivo entusiasmo como de abatimiento exagerado: les cuesta poco caer y levantarse, a menudo excediéndose en sus actos y dispuestos siempre a sentir, antes que a pensar" ${ }^{44}$.

La descripción se corresponde con los estereotipos de la época y con la siempre aludida contraposición entre la racionalidad de los pueblos civilizados -los europeos-y la sensualidad irracional de los bárbaros. Sin embargo, y a pesar de la imagen de inmovilismo y de estancamiento que suele ofrecer Tocqueville de los árabes, no considera que sea necesariamente un estancamiento definitivo. Los estímulos exteriores, como la presencia de los franceses, pueden poner en marcha el motor de la evolución. Tocqueville compara a menudo la situación de las tribus árabes con la Edad Media europea, en la que los señores feudales se enseñoreaban de tierra y súbditos y guerreaban con los vecinos. Sin embargo, continúa, Abd-el Kader, para optimizar la guerra contra Francia, está acabando con los todopoderosos jefes de tribu, para unificar fuerzas bajo su mando, como hicieron los reyes europeos en los siglos $\mathrm{XV}_{\text {y XVI }}{ }^{45}$. La evolución es posible y es quizá el aislamiento el que la ha impedido.

Hay un último argumento que conecta al Tocqueville de la Democracia en América, con el partidario del colonialismo. Las sociedades democráticas tienden a sacrificar la grandeza a la tranquilidad, "los asuntos grandes a los pequeños", se consuelan construyendo ferrocarriles y "logrando la prosperidad de cada particular, en un clima de paz, obtenida a cualquier precio" ${ }^{46}$. Esta tendencia, que en Estados Unidos se compensa por un gran amor a la libertad y una participación en la vida política local que hace a los individuos interdependientes, en Francia entrañan el peligro del despotismo, porque el afán por el dinero, por el bienestar y por los goces materiales "alejan y desvían la imaginación de los hombres de los negocios públicos" ${ }^{47}$. El orgullo nacional, la búsqueda de la gloria, el patriotismo en definitiva, puede ser un buen

\footnotetext{
${ }^{44}$ Ibid. pp. 131-35.

${ }^{45}$ Travail sur l'Algérie (1841), OC, Vol. III, 1, p. 223.

${ }^{46}$ Correspondance anglaise, Carta a John Stuart Mill de 18 de marzo de 1841, en OC, Vol. VI, 1, p. 33 .

47 El Antiguo Régimen y la Revolución. Madrid, Alianza Editorial, 1982, vol. I, pp. 50.
} 
sustituto de la virtud política que no puede ya encontrarse en las sociedades democráticas, ofreciendo a los ciudadanos una gran empresa que les lleve a asociarse, a involucrarse en la esfera pública, favoreciendo la unidad de acción y elevándolos por encima de los pequeños intereses personales y cotidianos. El proyecto colonial, imbuido de nacionalismo, puede ser esa gran empresa.

\section{Los pueblos sufrientes}

Y ¿cuál es el futuro de los pueblos subyugados de una u otra forma por la expansión europea? Tocqueville no es un apóstol de la mission civilizatrice, como lo habían sido los partidarios de la colonisation nouvelle del cambio de siglo $^{48}$. En sus primeras reflexiones sobre Argelia, desde Francia, cree posible que se realice algún día la fusión entre ambos pueblos ${ }^{49}$, un optimismo que la realidad que contempla sobre el terreno se encargará de desmentir. Y aunque termine abogando por dos legislaciones distintas puesto que existen dos sociedades separadas, yuxtapuestas, sin ningún lazo de unión entre ellas, la idea primera de la fusión de pueblos y culturas indica que tampoco fue un racista biológico, como alguno de sus contemporáneos.

Por eso, cuando aborda la cuestión de la abolición de la esclavitud está lejos de ver en los africanos una raza destinada a la sumisión. En primer lugar porque piensa que el cristianismo hizo a los hombres iguales en dignidad ante Dios, y que los ideales de la Revolución francesa los hicieron iguales ante la $l^{2} y^{50}$. Un gran especialista en Tocqueville como Jean-Louis Benoît afirma incluso que todas las consideraciones que despliega para considerar a la esclavitud perniciosa para el desarrollo económico de las colonias, no son sino una mera estrategia para obtener el voto en la Cámara a favor de la abolición de los diputados menos preocupados por la moral y la justicia pero bien dispuestos en cambio a mejorar la producción en los territorios de ultramar ${ }^{51}$. Sin embargo, se le ha reprochado que sus reflexiones sobre las razas en el capítulo X del primer volumen de La democracia en América, ponen de manifiesto los límites de su pensamiento, y de todo el liberalismo, sobre el problema de la convivencia racial. Tocqueville aceptaría la igualdad ante la ley

48 Bernard Gainot, "La Décade et la "colonisation nouvelle", en Annales historiques de la Révolution française, 339 (2005), pp. 1-16; M. Dorigny, "Intégration républicaine des colonies et projets de colonisation de l'Afrique: civiliser pour émanciper? », en Revue française d'histoire d'outre-mer, 238-239 (2000), pp. 89-105 ; Pernille Roge, "L'économie politique en France et les origines intellectuelles de 'La Mission Civilisatrice' en Afrique», en Dix-huitième siècle, 44, (2012), p. 117-130.

49 Deuxième lettre sur l'Algerie, OC, Vol. III, 1, p. 151.

50 Intervention dans la discussion de la loi sur le régime des esclaves dans les colonies, Discurso de 30 de mayo de 1845, en $O C$, Vol. III, 1, pp. 124-125.

51 Jean-Louis Benoît, Tocqueville moraliste, Paris, Honoré Champion, 2004, pp. 103 y ss. 
pero asumiría la desigualdad social que supone considerar la diferencia de raza como un estigma que recordará siempre el origen esclavo de los negros, tal como observa en los estados abolicionistas de Norteamérica. Esta "dualidad" en el concepto de igualdad le lleva a una cierta ambigüedad que le hace merecedor del calificativo de "racista", aun situado en una actitud de denuncia de la esclavitud y compasión hacia los sufrimientos de los esclavos ${ }^{52}$.

¿Ambigüedad o pesimismo lúcido? Afortunadamente la profecía de un enfrentamiento bélico entre blancos y negros en suelo norteamericano no se ha cumplido, salvo que la veamos realizada en la Guerra de Secesión de 186165 , lo que sería una simplificación excesiva. Pero no es menos cierto que los prejuicios raciales están lejos de su desaparición en la sociedad americana del siglo XXI. Es cierto que en sus artículos y en sus intervenciones parlamentarias se preocupa sobre todo de las cuestiones políticas, de las medidas a adoptar para una transición adecuada hacia la libertad de los esclavos de las colonias, pero disponemos también de su correspondencia con Gobineau, en la que sus juicios son más tajantes. Tocqueville había nombrado a Gobineau jefe de su gabinete cuando fue Ministro de Asuntos Exteriores, en 1849, al parecer por sus conocimientos de alemán. Sin embargo nunca coincidieron en sus opiniones filosóficas, sociales o políticas, y las tesis de Gobineau sobre las razas aceleró el distanciamiento entre ambos. Cuando el conde le envió, en 1853, un ejemplar de su Essai sur l'inegalité des races humaines para conocer su opinión, Tocqueville se mostró extremadamente crítico, hasta el punto de que se negó a recomendar su nombre para la Academia de Ciencias Morales y Políticas ${ }^{53}$.

Lo que más irritaba a Tocqueville de las tesis de Gobineau era el fatalismo que encerraban, al negar al ser humano, como individuo y como miembro de una comunidad, la posibilidad de influir en su destino a través de su educación, sus sentimientos, sus virtudes o su voluntad. Reducir todos estos elementos a la sangre y a la herencia le parece una simplificación propia de su época, en la que reinan la apatía, la indiferencia y la falta de energía y de esfuerzo, como reacción negativa a la frustración y a la fatiga de las revoluciones:

"Después de haber creído que podíamos transformarnos, nos creemos ahora incapaces de reformarnos; después de haber tenido un orgullo desmedido, hemos caído en una humildad que no lo es menos; pensábamos poderlo todo, hoy pensamos que no podemos nada, y nos complacemos en creer que la lucha y el esfuerzo son ya inútiles, y que nuestra sangre, nuestros músculos y nervios siempre serán más fuertes que nuestra voluntad y virtud. Es ésta, precisamente, la gran enfermedad de nuestro tiempo; enfermedad totalmente opuesta a la

${ }^{52}$ Curtis Stokes, "Tocqueville and the problem of Racial Inequality" en The Journal of Negro History, Vol. 75, núm. 1/2 (Winter-Spring 1990), pp. 1-15.

${ }^{53}$ Fotini Assimacopoulou, "Arthur de Gobineau commenté par Alexis de Tocqueville", en The Tocqueville Review/La Révue Tocqueville, Vol. XXII, núm. 2 (2001), pp. 197-219.

Araucaria. Revista Iberoamericana de Filosofia, Politica, Humanidades y Relaciones Internacionales, año $21, \mathrm{n}^{\circ} 42$. Segundo semestre de 2019. Pp. 399-421. ISSN 1575-6823 e-ISSN 2340-2199 doi: 10.12795/araucaria.2019.i42.17 
que sufrieron nuestros padres. Su libro, sea cual sea la forma en que presente usted las cosas, la favorece en lugar de combatirla; aunque usted no lo pretenda empuja a la indolencia el alma de nuestros contemporáneos, ya excesivamente indolente" ${ }^{\prime 4}$.

Las tesis de Gobineau, además, no solo son erróneas sino peligrosas para cualquier proyecto que contemple la mejora de las condiciones de vida de los pueblos no europeos, tanto si se trata de antiguos esclavos como de sociedades que viven todavía sometidas a condiciones de barbarie o de servidumbre:

\begin{abstract}
“Qué interés puede haber en persuadir a pueblos abúlicos, que viven en la barbarie, en la molicie o en la servidumbre, que son así por la naturaleza de su raza y que por lo tanto nada puede hacerse para mejorar su condición, cambiar sus costumbres o modificar su gobierno?;Acaso no ve usted que de su doctrina surgen, de manera natural, todos los males que la desigualdad permanente engendra, el orgullo, la violencia, el desprecio hacia el semejante, la tiranía y la abyección bajo todas sus formas?"55.
\end{abstract}

A pesar de tantos problemas, el destino de los africanos parece menos trágico que el de los amerindios de América del Norte.

Todo lo que pueda tener Tocqueville de romántico se refugia en su visión desgarrada de los indígenas de las grandes praderas. Junto con Beaumont cabalgó muchos días "en pays sauvage” para buscar información directa sobre un pueblo condenado a la extinción ${ }^{56}$. Con los relatos de Chateubriand y de Fenimore Cooper en mente, Tocqueville quiso ver en los indios americanos a la vez la decadencia y la gloria de una comunidad orgullosa, indomable y condenada a la desaparición. El africano, sometido por la fuerza, está “situado en los últimos bordes de la servidumbre", el indio, en cambio, "en los límites extremos de la libertad" 57 . "No hay indio tan miserable que, bajo su choza de corteza, no alimente una soberbia idea de su valor individual. Considera ocupaciones envilecedoras los trabajos de la industria, compara al labrador al buey que traza su surco y en cada una de nuestras artes percibe solamente trabajos de esclavo" 58 . Y, aunque capta todo el drama que hay detrás de esta situación, no puede reprimir una admiración llena de nostalgia de una época en que la libertad envolvía a la nobleza, dedicada solo, como los amerindios, a la guerra, la caza y la fiesta, y no se manchaba con los asuntos triviales de labradores,

${ }^{54}$ Lettre du 20 décembre 1853 à Gobineau, OC., Vol. IX, p. 205.

55 Lettre du 17 novembre 1853 à Gobineau, OC, Vol IX, p. 203.

56 Denys Delâge, Catherine Desbarats y Jean-Philippe Warren, "Alexis de Tocqueville en pays "sauvage", en The Tocqueville Review/La Revue Tocqueville, Vol. XXXVI, 2( 2015) pp. 175-204. Un estudio muy detallado de los encuentros de Tocqueville y los amerindios: Jean-Patrice Lacan, Les indiens de Tocqueville. Témoignages et réflexions sur l'Amérique indienne des années 1830. L'Harmatan, Paris, 2013.

${ }^{57}$ La democracia..., Vol. I, p. 310.

58 Ibid, p. 317.

Araucaria. Revista Iberoamericana de Filosofía, Política, Humanidades y Relaciones Internacionales, año $21, \mathrm{n}^{\circ} 42$. Segundo semestre de 2019. Pp. 399-421. ISSN 1575-6823 e-ISSN 2340-2199 doi: 10.12795/araucaria.2019.i42.17 
tenderos y negociantes que solo comen el pan que consiguen con su trabajo: "La caza y la pesca le parecen las únicas ocupaciones dignas de un hombre. El indio, en el fondo de la miseria de sus bosques, alimenta las mismas ideas las mismas opiniones que el noble de la Edad Media en su castillo fortificado y para terminar de parecérsele solo le falta hacerse conquistador" 59 . Y cree incluso que si hubiera sido Francia la ocupante del territorio norteamericano, el indio hubiera reconocido en sus invasores la búsqueda de la gloria militar, el gusto por la aventura, su carácter intrépido, que les asemejaba a ellos mismos, y que distingue a Francia de los plebeyos de origen británico que roturan sin cesar las tierras del nuevo mundo ${ }^{60}$.

Pero, más allá de la ensoñación nostálgica y nacionalista, Tocqueville siempre es lúcido en el lamento por un pueblo desposeído de sus costumbres, que no desea abrazar la vida de sus invasores, que no puede competir con ellos ni aunque deseara imitarles y al que se persigue continuamente aun en sus últimos reductos. Ya no es posible la vida salvaje, pero todavía no es posible la vida civilizada. La civilización necesita tiempo, y los amerindios carecen de él.

\section{Las ambiguedades de la civilización}

Este breve recorrido por las miradas que dirige Tocqueville a los pueblos y a las culturas no occidentales nos muestra una doble preocupación. Por un lado, por el papel de Francia en la nueva geopolítica derivada de la decadencia del Imperio otomano; por otra, y no en menor importancia sino de forma paralela, por el presente y el futuro de la civilización en un mundo que se percibía nuevo $\mathrm{y} \sin$ fronteras.

Nacionalismo, imperialismo... sin duda. Pero hay algo más. Desde la revolución de Haití, desde la arenga de Napoleón en las Pirámides, desde la prohibición de la trata de esclavos por el tratado de París..., Europa, y Francia con ella, cobra conciencia de que las fronteras se están alejando, de que la producción y el comercio están entrando en una nueva era, de que se requieren nuevas formas de hacer política.

Las famosas páginas de la Introducción a La democracia en América, en las que Tocqueville vaticina la expansión del sistema democrático por Norteamérica y Europa primero, por el resto del mundo después, entrañan las claves para la comprensión global de las páginas que dedica a las culturas no occidentales. La igualdad de condiciones está en los designios de la Divina Providencia y de la Historia y se impondrá antes o después. Ya no es posible elegir y solo podemos adaptarnos lo mejor que sepamos a su reinado. “Querer

\footnotetext{
${ }^{59}$ Ibid. p. 317.

${ }^{60}$ Denys Delâge... Op. cit. p. 182.
} 
contener la democracia parecería entonces enfrentarse con Dios mismo, y a las naciones no les quedaría otro remedio que someterse al estado social que les impone la Providencia"61.

¿Y qué igualdad espera a los pueblos oprimidos o marginados por liberales y demócratas occidentales? Cuando Tocqueville se inclina ante los designios de la Divina Providencia está pagando tributo a lo que sus contemporáneos, desde Condorcet, llamaban y, sobre todo, llamarán Progreso: leyes inexorables de la Historia a las que no cabe sustraerse. Y esas leyes inexorables nos han llevado, y nos siguen llevando, del salvajismo a la barbarie y de la barbarie a la civilización, aunque esta rígida división deba esperar todavía algunas décadas ${ }^{62}$. La igualdad de condiciones es quizá el último escalón de la vida civilizada,

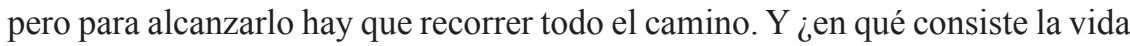
civilizada? Por supuesto no hay un repertorio de elementos civilizatorios en la obra tocquevilliana, pero sí algunos indicios. Los pueblos sedentarios están más cerca de la civilización que los pueblos nómadas pastores o cazadores, y por eso los amerindios no tienen ninguna posibilidad de sobrevivir entre los colonos agricultores; tendrían primero que aprender a cultivar la tierra, pero la marcha acelerada de la expansión europea no les deja tiempo para afrontar con éxito esta etapa. Los árabes argelinos no están fijados a la tierra y carecen así de títulos de propiedad de la misma y la marea colonizadora los puede desposeer, casi igual que a los amerindios. Los pueblos monoteístas tienen un sentido religioso más desarrollado que los politeístas, por eso el Islam presenta más ventajas que la religión hindú. Los pueblos vinculados por lazos comunitarios de tipo nacional sobreviven mejor que los divididos por lealtades tribales o solo son fieles a un pequeño grupo de iguales, y por eso la India ha sido presa fácil de los británicos. Solo los pueblos abiertos al comercio y a la comunicación serán admitidos en el concierto de las naciones, y por eso los chinos pueden ser obligados a esa integración.

La lista podría alargarse todavía más pero siempre nos estaría indicando los difíciles recovecos de ese camino que ha de ser inevitablemente recorrido por todos. ¿Pueden y deben los europeos empujar a los caminantes para que alcances sus metas más deprisa? No hay en Tocqueville mención expresa de un proyecto civilizador. Si antes de viajar a Argelia alberga el proyecto de una fusión de los pueblos árabe y francés en el suelo de la antigua Regencia, la realidad le impone la necesidad de vidas separadas, y no va más allá. No hay nunca una imposibilidad de tipo biológico, como lo muestra su crítica al racismo de Gobineau, y sí fuertes críticas a veces a la manera cómo se conduce el gobierno francés en la colonia argelina, que acabará fracasando en su tarea si no rectifica: "He vuelto de África con la dolorosa idea de que en este momento

${ }^{61}$ La democracia... Introducción, p. 10.

${ }^{62}$ Lewis Henry Morgan, Ancient Society (1877), Londres, MacMillan \& Company, 1877. 
nosotros hacemos la guerra de un modo harto más bárbaro que los propios árabes. Hoy por hoy la civilización se encuentra de su lado"63.

¿Significa que los franceses deben mejorar la condición bárbara de los argelinos y cumplir así una tarea moral? No hay muchas más evidencias.

Hay quien ha sostenido que todo forma parte de una gran plan en el ideario de Tocqueville: una nueva ciencia política para un mundo nuevo abocado a la democracia y un proyecto colonizador para expandirla ${ }^{64}$. Una percepción tan clara del destino de todos los hilos que tejen el presente no está explícita en la obra de Tocqueville. Entre la interpretación puramente imperialista y el modelo acabado de proyecto civilizatorio y democrático, quizá podemos encontrar a un filósofo sensible a los cambios que se están produciendo a su alrededor, eurocéntrico pero interesado en las creencias y costumbres de otros pueblos, nacionalista pero crítico con la actuación de sus compatriotas, con gran curiosidad por quienes son distintos y con fuertes dosis de lucidez.

${ }^{63}$ Travail sur l'Algérie, OC, Vol. III, 1, p. 226.

${ }^{64}$ Ewa Atanassow, "Colonization and Democracy: Tocqueville reconsidered", en American Political Science Review, 111, 1 (2017), pp. 83-96. 


\section{Referencias bibliográficas:}

Anquetil-Duperron, Abraham-Hyacinthe, Législation Orientale. Ouvrage dans Lequel, en montrant Quels Sont en Turquie, en Perse et dans l'Hindoustan, les Principes Fondamentaux du Gouvernement ..., Amsterdam, M.M. Rey, 1778.

Assimacopoulou, Fotini, "Arthur de Gobineau commenté par Alexis de Tocqueville", en The Tocqueville Review/La Révue Tocqueville, Vol. XXII, 2 (2001).

Atanassow, Ewa, Colonozation and Democracy: Tocqueville Reconsidered", en American Political Science Review, 111, 1 (2017).

Benoît, Jean-Louis, Tocqueville moraliste, Paris, Honoré Champion, 2004.

Benoît, Jean-Louis (ed.), Alexis de Tocqueville, Notes sur le Coran et autres textes, edición electrónica: http://louprebel.fr/blog/documents/ tocqueville_notes_coran.pdf, consultada el 14 de Agosto de 2018.

Delâge, Denys; Desbarats, Catherine y Warren, Jean-Philippe, "Alexis de Tocqueville en pays 'sauvage"”, en The Tocqueville Review/La Revue Tocqueville, Vol. XXXVI, 2

(2015).

Díez del Corral, Luís, El liberalismo doctrinario, Madrid, Instituto de Estudios Políticos, 1945.

Dorigny, Marcel, "Intégration républicaine des colonies et projets de colonisation de l'Afrique: civiliser pour émanciper? », en Revue française d'histoire d'outre-mer, 238-239 (2000).

Duan, Demin, "Reconsidering Tocqueville's Imperialism", en Ethical perspectives, 17 , núm. 3 (2010).

Gainot, Bernad, "La Décade et la 'colonisation nouvelle", en Annales historiques de la Révolution française, 339 (2005).

Jaume, Lucien, Tocqueville, les sources aristocratiques de la liberté, Paris, Fayard, 2008.

Lacan, Jean-Patrice, Les indiens de Tocqueville. Témoignages et réflexions sur l'Amérique indienne des années 1830. L'Harmatan, Paris, 2013.

Lawlor, Mary, Alexis de Tocqueville in the Chamber of Deputies. His Views on Foreing and Colonial Policy, Whasington D.C., The Catholic University of America Press, 1959.

Lorcin, Patricia M.E., Kabyles, Arabes, Français: identités coloniales, Presses de l'Université de Limoges, 2005.

Marsh, Kate, India in the French Imagination. Peripheral Voices, 1754-1815. Empires in perspective, $\mathrm{n}^{\mathrm{o}}$ 8. Pickering and Chatto, Londres, 2009.

Mélonio, Françoise, "Tocqueville, la Chine et le Japon", en The Tocqueville Review/La Revue Tocqueville, vol. XXXVIII, 1(2017). 
Mill, James, The History of British India, segunda edición, London, Baldwin, Cradock and Joy, 1820, libro II.

Mill, John Stuart, Collected Works, J.M. Robson General Editor, vol. XXI, Essays on Equality, Law, and Education, Routledge \& Keagan Paul, 1984 Mohan, Jyoti, "British and French Ethnographies of India: Dubois and His English Commentators", en French Colonial History, 5, (2004).

Montesquieu, Charles Louis de Secondat de, De l'esprit des lois

Pitts, Jennifer, "Empire and Democracy: Tocqueville and the Algeria Question", en The Journal of Political Philosophy, vol. 8, 3 (2000).

-- $\quad$ A Turn to Empire. The rise of Imperial Liberalism in Britain and France, Princeton University Press, 2005.

Roge, Pernille, "L'économie politique en France et les origines intellectuelles de 'La Mission Civilisatrice' en Afrique», en Dix-huitième siècle, 44, (2012).

Sanchez-Mejía, María Luisa, "Colonialismo y alteridad: el debate racial y cultural en la conquista de Argelia”, en Araucaria. Revista Iberoamericana de Filosofía, Politica y Humanidades, 36 (2016)

Simonde de Sismondi, J.C.L., Nouvelles réflexions sur la traite des négres, Géneve, Paris, J.J. Paschoud, 1914.

Stokes, Curtis, "Tocqueville and the problem of Racial Inequality" en The Journal of Negro History, 75 (1990).

Tocqueville, Alexis de, Euvres Complètes, édition définitive publiée sous la direction de J-P. Mayer, Paris, Gallimard, 1962. Vols:

-- $\quad$ III, Écrits et discours politiques, 1 y 2.

-- VI, 1. Correspondance anglaise. Correspondance d'Alexis de Tocqueville avec Henry Reeve et John Stuart Mill.

-- VI, 2. Correspondance anglaise. Correspondance et conversations d'Alexis de Tocqueville et Nassau William Senior.

-- IX, Correspondance d'Alexis de Tocqueville et d'Arthur de Gobineau.

-- XIII, Correspondance d'Alexis de Tocqueville et de Louis de Kergorlay.

-- El Antiguo Régimen y la Revolución. Madrid, Alianza Editorial, 1982.

-- La democracia en América, edición crítica preparada y traducida por Eduardo Nolla, Madrid, Aguilar, 1988.

Welch, Cheryl, "Colonial Violence and the Rethoric of Evasion. Tocqueville on Argelia", en Political Theory, 31 (2003).

-- “Out of Africa: Tocqueville's Imperials Voyages", [en Chistine Dunn Henderson coord. Tocqueville Voyages, Liberty Fund, 2014]. 
